\title{
Experimental Investigation of a Cryogenically Cooled Oxygen- mist Near-dry Wire-cut Electrical Discharge Machining Process
}

\author{
Boopathi Sampath $1,{ }^{*}-$ Sureshkumar Myilsamy2 \\ ${ }^{1}$ Muthayammal Engineering College, Department of Mechanical Engineering, India \\ 2Bannari Amman Institute of Technology, Department of Mechanical Engineering, India
}

In this paper, a novel method of cryogenically cooled (low-temperature nitrogen gas) wire tool is used during the oxygen-mist near-dry wire-cut electrical discharge machining (NDWEDM) process to cut Inconel 718 alloy material. The current, pulse-width, pulse-interval, and flow rate are the controllable variables for response characteristics, such as the material removal rate (MRR) and wire wear ratio (WWR). The Box-Behnken method is applied to design the experiments to collect the observations from experiments. The mathematical models for each response were developed using significant individual, interaction, and quadratic terms by the sequential sum of the square test. The response surfaces were developed. It was revealed from the analysis that $52.92 \%$ of current, $24.63 \%$ of Pulse-width, $12.81 \%$ of pulse- interval and $5.75 \%$ of flow rate contributed to MRR, while $14.89 \%$ of current, $9.75 \%$ of pulse-width, $62.20 \%$ of pulse-interval, and $5.44 \%$ of flow rate contributed to WWR. The pulse-width has more contribution on MRR due to the long period of spark between the wire and work materials. It was also observed that the pulse-interval has more effect on WWR due to the more ideal period (high spark-pause-time) between two consecutive hightemperature sparks in the wire tool. The wear of the wire tool has been analysed using scanning electron microscopy (SEM) photographs. The desirability principles were first applied to obtain multi-objective solutions with a combination of process parameters to achieve the optimal values of both responses. The predicted combination of results has been validated by data that were collected from confirmation experiments. Keywords: cryogenically cooled, oxygen-mist, near-dry, wire-cut EDM, MRR, WWR, Box-Behnken method

\section{Highlights}

- A novel method of cryogenically cooled (low-temperature nitrogen gas) wire electrode tool in the oxygen-mist near-dry wire-cut electrical discharge machining (NDWEDM) process was experimented with to cut the Inconel 718 alloy material.

- Wire wear ratio and material removal rate of cryogenically cooled near-dry WEDM process was first investigated in this research.

- It was revealed that the pulse-interval has more effect on wire wear ratio due to a more ideal period (high spark-pause-time) between two consecutive high-temperature spark in the wire tool.

- $\quad$ The wear of the wire tool has been analysed using Scanning Electron Microscopy test photographs.

- $\quad$ The desirability principles were first applied to obtain the multi-objective solutions to optimize both responses.

\section{INTRODUCTION}

In an unconventional machining process, the relationships between manufacturing parameters and environmental impact are developed to analyse the material removal mechanics, tool change, minimum rejections in production, and the effects of cuttingfluid flow [1]. The environmental impact of machining processes should be analysed for minimizing environmental impacts by the modification of existing technology and the development of new manufacturing methods [2]. In these aspects, research into the modification of EDM and WEDM processes was developed to make a trade-off between machining performance and machining pollutions [3]. The analytical relationship of EDM processes was developed to reveal the wear of the tool and workpiece, the dielectric fluid flows, and toxicity and flammability [3] and [4]. The inferences of cooling electrode wear and surface roughness of the workpiece have been investigated by changing process parameters, such as voltage, pulse-width, current, and pulse-interval [5] and [6]. The parametric analysis of dry electric discharge machining of mild steel was investigated, and response models were developed using response surface methodology [7]. Generally, the machining performance of the dry EDM process is very low compared to the conventional process. It was revealed that the tool wear of the dry EDM process is significantly reduced by cryogenic cooling of the electrode and workpiece [8]. The mechanism of the gas-liquid-powder mixture in EDM was investigated in both dry and near-dry processes to improve material erosion. The cryogenically tested brass wire produces a $22.55 \%$ greater material removal rate (MRR) compared to an untreated brass wire [9]. A parametric study was performed using a molybdenum wire tool and tool steel workpiece with an air dielectric to investigate the influence of air-mist pressure, voltage, pulse-duration, pulse-width, and current on the MRR and $\mathrm{Ra}$ using the Taguchi technique [5] and [10]. Later, the oxygen gas near-dry WEDM experiments were conducted using Taguchi's L27 orthogonal array and multi-objective artificial bee colony (MOABC) 
algorithm [11] and [12]. Cryo-treated wire electrodes, liquid nitrogen, and zinc-coated brass wires were investigated to reduce the tool wear rate for the green environment [4], [13] to [15]. Recently, the electrical conductivity of cryo-cooled molybdenum wire has been increased by cryogenic treatments [16]. However, no synchronized cryo-treated gas-liquid mixer was found in the near-dry EDM and WEDM process.

In this research, the data from 29 observations from cryogenically cooled oxygen-mist near-dry WEDM experiments were collected. The collected data are used to predict the data for better results of the near-dry WEDM process. The significant process parameters were identified to improve the quality of cutting processes. The desirability approach is used to convert the single-objective problem into a multiobjective optimization problem. The WEDM machine manufacturer and operators utilize the optimum results to set the optimal process parameters for the best machining performances.

\section{EXPERIMENTATION}

\subsection{Experimental Setup}

The cryo-cooled wire electrode setup was developed in numerically controlled (NC) wire-cut electrical discharge machining. Liquid nitrogen was stored in a dewar flask to maintain the cryogenic temperature. The molybdenum wire was cooled on both sides of the electrode movements. The oxygen and dielectric fluid mixture are used as a working medium in the reciprocating WEDM machine. Based on trial experiments, the input parameters and their significance levels are identified. The billet size of 718 is $50 \mathrm{~mm} \times 50 \mathrm{~mm} \times 5 \mathrm{~mm}$ Inconel 718 is used as work material for near-dry WEDM machining processes. The experimental setup of cryo-cooled near-dry WEDM is shown in Fig. 1. Sub-123 K of liquid nitrogen was stored. The $253 \mathrm{~K}$ temperature and $10 \mathrm{~g} / \mathrm{s}$ mass flow rate of $\mathrm{N}_{2}$ were used to cool the molybdenum wire during the cutting process. The oxygen and the dielectric fluid mixture were used as a dielectric medium in reciprocating the WEDM machine. The $M R R$ in $\left[\mathrm{mm}^{3} / \mathrm{min}\right]$ can be calculated by the volume of materials removed concerning time using Eqs. (1) and (2).

$$
\begin{gathered}
\text { Kerf }=\text { wire diameter } \times(2 \times \text { sparking gap }), \\
M R R=\frac{\text { thickness } \times \text { Kerf } \times \text { length of } \text { cut }}{\text { time }} .
\end{gathered}
$$

The wire wear ratio (WWR) has been measured from the loss of wire materials during the cutting process concerning the time, and the initial weight of wire is to be taken before machining process [17] (Eq. (3)).

$$
W W R=\frac{\text { weight loss of wire }}{\text { initial weight of wire }} .
$$

Based on exploratory experiments, the input parameters and their significance levels are identified. The levels of each process variable are tabulated in Table 1. The near-dry WEDM experiments are conducted [18], and the MRR and WWR values observed through the experiments are shown in Table 2.

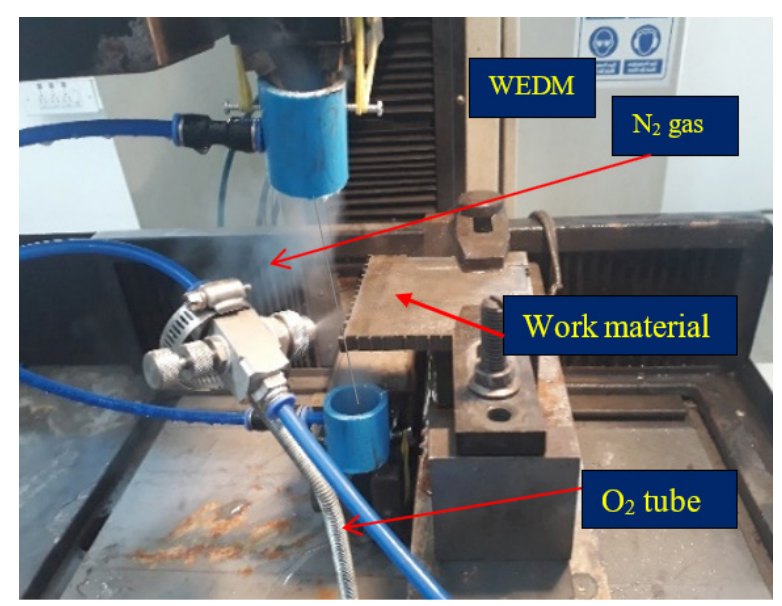

Fig. 1. Cryogenically cooled oxygen-mist near-dry WEDM

\begin{tabular}{|c|c|c|c|c|c|c|}
\hline Description & Symbol & Parameter & Units & Low & High & Mean \\
\hline \multirow{4}{*}{ Input parameters } & $C$ & Current & A & 3 & 5 & 4 \\
\hline & $P W$ & Pulse-width & $\mu \mathrm{s}$ & 15 & 25 & 20 \\
\hline & $P I$ & Pulse-interval & $\mu \mathrm{s}$ & 45 & 75 & 60 \\
\hline & $F$ & Flow rate & $\mathrm{ml} / \mathrm{min}$ & 10 & 20 & 15 \\
\hline Dielectric medium & \multicolumn{6}{|c|}{ Oxygen gas mixed with water } \\
\hline Wire treatment & \multicolumn{6}{|c|}{ Cryogenic Nitrogen gas during the machining process } \\
\hline Output parameters & \multicolumn{6}{|c|}{$M R R$ in $\left[\mathrm{mm}^{3} / \mathrm{min}\right]$, and $W W R$} \\
\hline
\end{tabular}
experimental set

Table 1. Parameter and Machine Setting level 
Table 2. Design of Experiments and observations using Box-Behnken method

\begin{tabular}{ccccccc}
\hline Exp. No. & $C$ & $P W$ & $P I$ & $F$ & $M R R$ & $W W R$ \\
\hline 1 & 3 & 20 & 75 & 15 & 6.13 & 0.464 \\
\hline 2 & 5 & 20 & 75 & 15 & 9.45 & 0.626 \\
\hline 3 & 4 & 15 & 60 & 20 & 8.38 & 0.643 \\
\hline 4 & 4 & 20 & 45 & 10 & 9.28 & 0.994 \\
\hline 5 & 4 & 25 & 60 & 10 & 9.57 & 0.921 \\
\hline 6 & 4 & 20 & 60 & 15 & 9.12 & 0.783 \\
\hline 7 & 4 & 20 & 60 & 15 & 9.09 & 0.724 \\
\hline 8 & 4 & 15 & 75 & 15 & 7.12 & 0.424 \\
\hline 9 & 5 & 20 & 60 & 20 & 10.9 & 0.829 \\
\hline 10 & 3 & 60 & 15 & 8.51 & 0.864 \\
\hline 11 & 3 & 25 & 60 & 10 & 6.58 & 0.745 \\
\hline 12 & 4 & 45 & 15 & 10.91 & 0.991 \\
\hline 13 & 4 & 25 & 75 & 10 & 7.78 & 0.635 \\
\hline 14 & 3 & 20 & 45 & 15 & 7.76 & 0.848 \\
\hline 15 & 4 & 60 & 10 & 7.38 & 0.767 \\
\hline 16 & 4 & 15 & 45 & 15 & 8.67 & 0.921 \\
\hline 17 & 4 & 75 & 20 & 8.74 & 0.478 \\
\hline 18 & 5 & 20 & 45 & 15 & 10.87 & 1.050 \\
\hline 19 & 5 & 20 & 60 & 10 & 9.44 & 0.934 \\
\hline 20 & 4 & 20 & 75 & 15 & 9.38 & 0.670 \\
\hline 21 & 5 & 25 & 60 & 15 & 10.77 & 0.872 \\
\hline 22 & 4 & 25 & 60 & 20 & 10.29 & 0.905 \\
\hline 23 & 5 & 20 & 60 & 15 & 9.47 & 0.913 \\
\hline 24 & 4 & 15 & 60 & 15 & 9.12 & 0.778 \\
\hline 25 & 4 & 20 & 15 & 9.11 & 0.78 \\
\hline 26 & 4 & 20 & 20 & 15 & 8.63 & 0.807 \\
\hline 27 & 4 & 20 & 15 & 15 & 6.02 & 0.502 \\
\hline 29 & 3 & 20 & 20 & 7.24 & 0.621 \\
\hline
\end{tabular}

\subsection{Design of Experiments}

The Box-Behnken method is used to conduct the experiments by design expert software. The BoxBehnken design is a self-determining quadratic design, which does not contain the partial factorial design. The designs have restricted capability related to the central composite designs. Five central points are repeated to avoid bios errors. The design uses 8 trails from $(2 \times 4=8)$ two levels of $k$ parameters, 16 trails of two factorial design $(24=8)$, and five repeated central points to calculate lack-of-fit. Twenty-nine sets of experiments were conducted, and the observed responses are tabulated in Table 2. Based on the analysis of the variance test, the significant individual and interaction and quadratic terms were identified [5]. Insignificant terms are eliminated from the model.
If the response is ' $f(x)$ ', the independent variables are $x_{1}, x_{2}, \ldots, x_{n}$, and the response model is developed by following general Eq. (4).

$$
\begin{gathered}
f(x)=\beta_{0}+\sum_{i=1}^{k} \beta_{0} x_{i}+\sum_{i=1}^{k} \sum_{j=1}^{k} \beta_{i j} x_{i} x_{j}+\ldots+\phi, \\
\text { and } i<j,
\end{gathered}
$$

where $\mathrm{k}$ is the number of process variables; $\beta_{0}, \beta_{i}$, and $\beta_{i j}$ are the model coefficients; $\phi$ is the statistical error, which represents variability by other noises.

\section{RESULT ANALYSIS AND DISCUSSIONS}

The sequential sum of the square test was used to select the optimum model for the analysis. Initially, the linear model is selected [12]. However, the model is not significant due to the coefficient of determination $\left(R^{2}\right)$ 
value of $M R R$ and $W W R$ is very low $\left(M R R R^{2}=0.072\right.$ and $\left.W W R R^{2}=0.81\right)$. The two factors interaction model $(2 F I)$ also did not fit with the solution due to the $R^{2}$ value of both models is minimum (MRR $R^{2}=0.608$ and $\left.W W R R^{2}=0.075\right)$. Then, the quadratic model of $M R R$ was selected due to the $R^{2}$ value of 0.998 of both responses. The insignificant terms of the models were eliminated from quadratic models. The lack of fit of the model is insignificant and thus acceptable. The cubic models of both responses were not selected due to more allies' terms in the models. The lack of fit tests of MRR and $W W R$ are shown in Tables 3 and 5 , respectively. The analysis of the variations of $M R R$ and $W W R$ concerning process parameters are shown in Tables 4 and 6, respectively. The regression models of $M R R$ and $W W R$ were developed to identify the inference of process variables as shown in Eqs. (5) and (6) respectively.

$$
\begin{aligned}
M R R & =-8.241+5.335 \times C+0.45 \times P W-0.065 \times P I \\
& -0.0575 \times F-0.0595 \times C \times P W \\
& +3.5 \times 10^{-3} \times C \times P I+0.04 \times C \times F \\
& -0.425 \times C^{2},
\end{aligned}
$$

$R^{2}=99.40 \%$, Adjusted $R^{2}=99.14 \%$, and Predicted $R^{2}=98.18 \%$.

$$
\begin{aligned}
& \begin{aligned}
W W R= & -0.529+0.501 \times C+0.061 \times P W \\
& -6.161 \times 10^{-3} \times P I+1.727 \times 10^{-3} \times F \\
& -0.0201 \times C \times P W+5.867 \times 10^{-4} \times P W \times P I \\
& -2.267 \times 10^{-4} \times P I \times F-1.298 \times 10^{-4} \times P I^{2},
\end{aligned} \\
& R^{2}=99.40 \%, \text { Adjusted } R^{2}=99.16 \%, \text { and } \\
& \text { Predicted } R^{2}=99.04 \% .
\end{aligned}
$$

The insignificant terms are eliminated from $M R R$ and $W W R$ regression models to improve the predicted $R^{2}$ and adjusted $R^{2}$. The regression models are used to plot the response surface between response and process variables. The influences of the interaction effects of process parameters have been studied using the response surfaces.

The response surface of $M R R$ for flow rate and current is shown in Fig. 2. It is also significantly enhanced by increasing the flushing flow rate due to the quick disposal of debris from the cutting zone. Fig. 3 shows that the response surface of $M R R$ by the pulse-width vs current. The $M R R$ is improved by the increase in spark current between work materials and wire due to high spark strength [19]. It was observed that the large increase in $M R R$ is seen from low pulsewidth to high value by enhancing spark strength, as shown in Fig. 4 [12]. However, the MRR is increased by reducing pulse-interval due to an increase in spark ideal time.

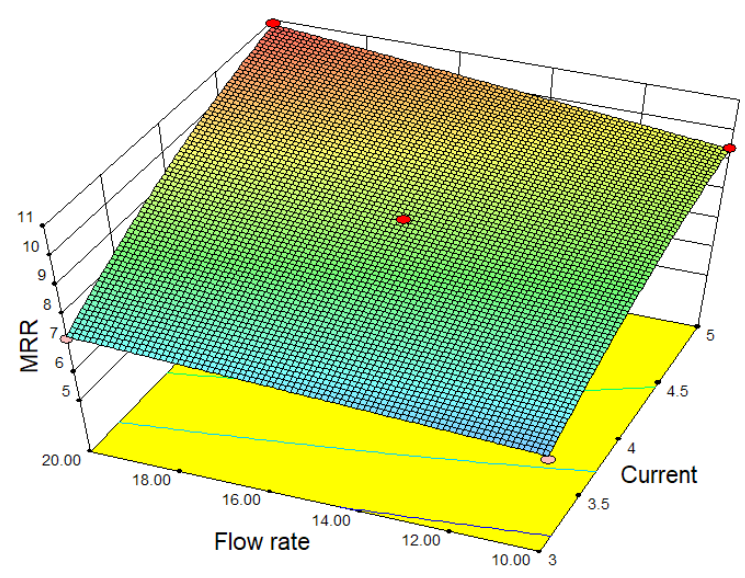

Fig. 2. Response surface for MRR concerning flow rate and current

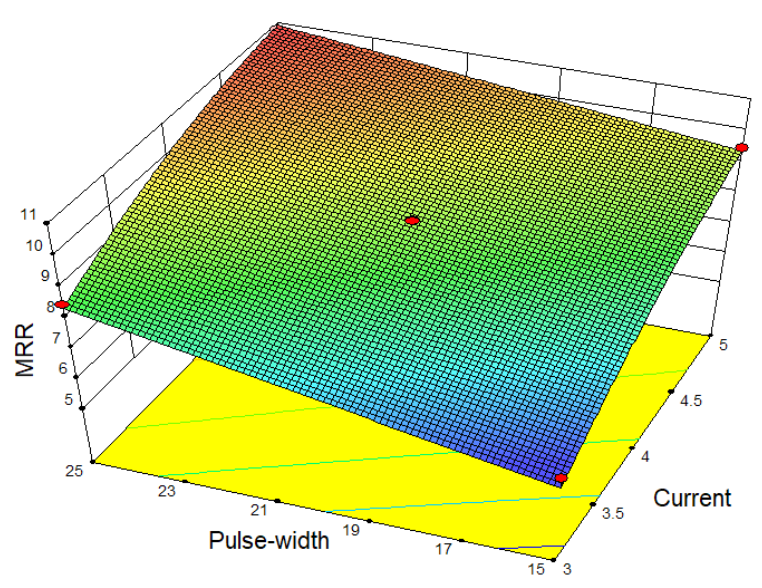

Fig. 3. Response surface for MRR concerning pulse-width and current

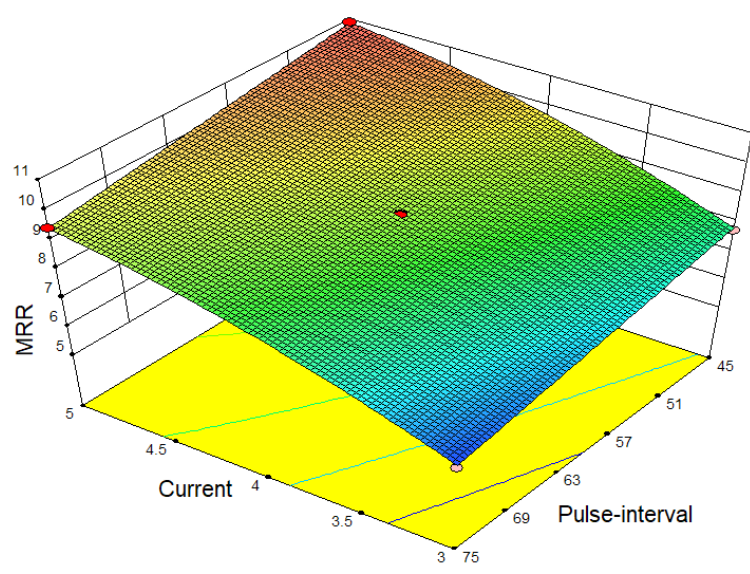

Fig. 4. Response surface for MRR concerning current and pulse-interval 
Table 3. Lack of fit test for material removal rate model

\begin{tabular}{lcccccc}
\hline Source & Sum of squares & Degree of freedom & Mean sum square & $F$-value & $p$-value $>F$ & Comments \\
\hline Linear & 2.040 & 20 & 0.102 & 4.383 & 0.081 & Insignificant \\
\hline $2 \mathrm{FI}$ & 1.513 & 14 & 0.108 & 4.644 & 0.075 & Insignificant \\
\hline Quadratic & 0.215 & 10 & 0.022 & 0.924 & 0.584 & Suggested \\
\hline Cubic & 0.036 & 2 & 0.018 & 0.775 & 0.520 & Aliased \\
\hline Pure Error & 0.093 & 4 & 0.023 & - & - & - \\
\hline
\end{tabular}

Table 4. Data analysis of material removal rate

\begin{tabular}{lcccccccc}
\hline Source & Sum of squares & Degree of freedom & Mean square & F-value & $p$-value $>F$ & Remarks & Contribution [\%] \\
\hline Model & 54.491 & 8 & 6.811 & 404.036 & $<0.0001$ & Significant & 99.39 \\
\hline Current $(C)$ & 29.016 & 1 & 29.016 & 1721.184 & $<0.0001$ & Significant & 52.92 \\
\hline Pulse-width $(P W)$ & 13.504 & 1 & 13.504 & 801.052 & $<0.0001$ & Significant & 24.63 \\
\hline Pulse-interval $(P I)$ & 7.023 & 1 & 7.023 & 416.571 & $<0.0001$ & Significant & 12.81 \\
\hline Flow rate $(F)$ & 3.152 & 1 & 3.152 & 186.962 & $<0.0001$ & Significant & 5.75 \\
\hline$C \times P W$ & 0.354 & 1 & 0.354 & 21.000 & 0.0002 & Significant & 0.65 \\
\hline$C \times P I$ & 0.011 & 1 & 0.011 & 0.654 & $0.4282^{*}$ & Not significant & 0.02 \\
\hline$C \times F$ & 0.160 & 1 & 0.160 & 9.491 & 0.0059 & Significant & 0.29 \\
\hline$C 2$ & 1.271 & 1 & 1.271 & 75.369 & $<0.0001$ & Significant & 2.32 \\
\hline Residual & 0.337 & 20 & 0.017 & - & - & - & - \\
\hline Lack of fit & 0.244 & 16 & 0.015 & 0.656 & 0.7580 & Not significant & - \\
\hline Pure error & 0.093 & 4 & 0.023 & - & - & - & - \\
\hline Cor total & 54.8281 & 28 & - & - & - & & - \\
\hline
\end{tabular}

Table 5. Lack of fit test for WWR model

\begin{tabular}{|c|c|c|c|c|c|c|}
\hline Source & Sum of squares & Degree of freedom & Mean square & $F$-value & $p$-value $>F$ & Comments \\
\hline Linear & 0.06 & 20.00 & 0.00 & 4.78 & 0.070 & Insignificant \\
\hline $2 \mathrm{FI}$ & 0.01 & 14.00 & 0.00 & 0.92 & 0.601 & Insignificant \\
\hline Quadratic & 0.00 & 10.00 & 0.00 & 0.11 & 0.998 & Suggested \\
\hline Cubic & 0.00 & 2.00 & 0.00 & 0.08 & 0.927 & Aliased \\
\hline Pure Error & 0.00 & 4.00 & 0.00 & - & - & - \\
\hline
\end{tabular}

Table 6. Data analysis of wire wear ratio

\begin{tabular}{|c|c|c|c|c|c|c|c|}
\hline Source & Sum of squares & Degree of freedom & Mean square & F-value & $p$-value $>F$ & Remarks & Contribution [\%] \\
\hline Model & 0.7747 & 8.0000 & 0.0968 & 411.8384 & $<0.0001$ & Significant & 99.40 \\
\hline Current $(C)$ & 0.1160 & 1.0000 & 0.1160 & 493.4670 & $<0.0001$ & Significant & 14.89 \\
\hline Pulse-width $(P W)$ & 0.0760 & 1.0000 & 0.0760 & 323.2220 & $<0.0001$ & Significant & 9.75 \\
\hline Pulse-interval $(P I)$ & 0.4848 & 1.0000 & 0.4848 & 2061.8105 & $<0.0001$ & Significant & 62.20 \\
\hline Flow rate $(F)$ & 0.0424 & 1.0000 & 0.0424 & 180.1662 & $<0.0001$ & Significant & 5.44 \\
\hline$C \times P W$ & 0.0406 & 1.0000 & 0.0406 & 172.6734 & $<0.0001$ & Significant & 5.21 \\
\hline$P W \times P I$ & 0.0077 & 1.0000 & 0.0077 & 32.9337 & $<0.0001$ & Significant & 0.99 \\
\hline$P I \times F$ & 0.0012 & 1.0000 & 0.0012 & 4.9162 & 0.0384 & Significant & 0.15 \\
\hline$P I^{2}$ & 0.0060 & 1.0000 & 0.0060 & 25.5181 & $<0.0001$ & Significant & 0.77 \\
\hline Residual & 0.0047 & 20.0000 & 0.0002 & & & - & 0.60 \\
\hline Lack of fit & 0.0023 & 16.0000 & 0.0001 & 0.2360 & 0.9842 & Not significant & - \\
\hline Pure error & 0.0024 & 4.0000 & 0.0006 & - & - & - & - \\
\hline Cor total & 0.7794 & 28.0000 & - & - & - & - & - \\
\hline
\end{tabular}

The minimization of $W W R$ is one of the goals of this study. The $W W R$ is minimum at the low value of pulse-interval and pulse-width due to fine and soft spark in the cutting zone, as shown in Fig. 5. While 
the increase in pulse-width, the spark strength is significantly increased with material removal rate and reduced the $W W R$. The increase in pulse-interval is increasing the $W W R$ due to the high spark pause time [5]. Fig. 6 shows the interaction effects of pulse-width and current on $W W R$. While increasing the spark current, the $W W R$ value is exploiting due to heave spark intensity [20] and [21]. Similarly, the $W W R$ value is also slowly increased due to the growing $M R R$ by fast flushing debris, as shown in Fig. 7.

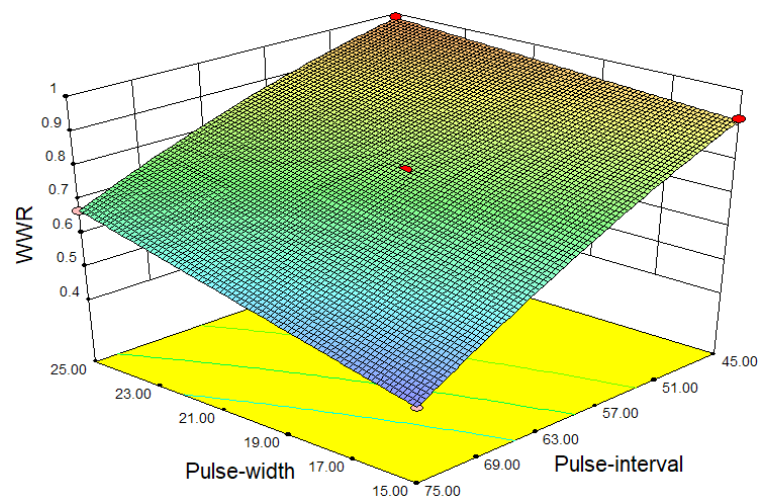

Fig. 5. Response surface for WWR concerning pulse-width and pulse-interval

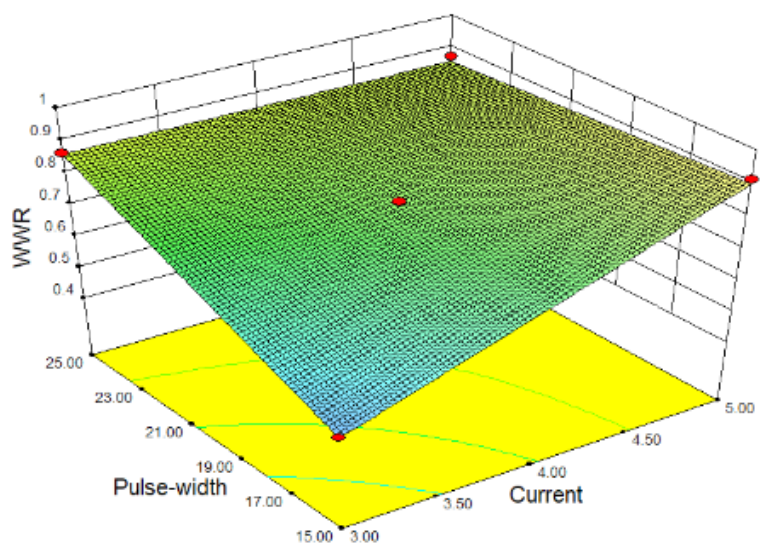

Fig. 6. Response surface for WWR concerning pulse-width and current

The wire wear ratio has been analysed with scanning electron microscopy (SEM) photograph, as shown in Fig. 8. It was observed that the wear on the wire is linearly along the axis due to the reciprocating wire longitudinally. The crater of materials in the wire is high at the point ' $\mathrm{P}$ ' due to the sudden supply of current to the wire. The path ' $Q R$ ' is sparking a portion of the wire, which is in direct with the workpiece. The high temperature along the 'QR' path due to frequent changes of power supply between the wire and workpiece causes to increase the wear ratio.
The path 'ST' is a non-spark portion of the wire tool, which has the minimum crater of wear.

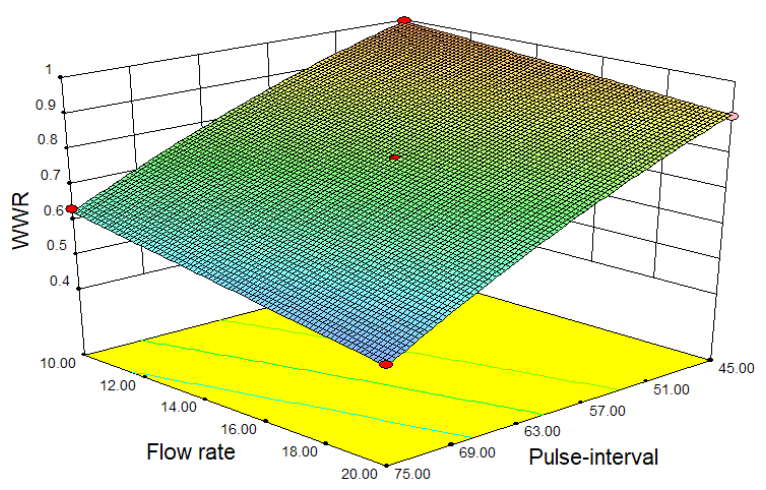

Fig. 7. Response surface for WWR concerning flow rate and pulseinterval

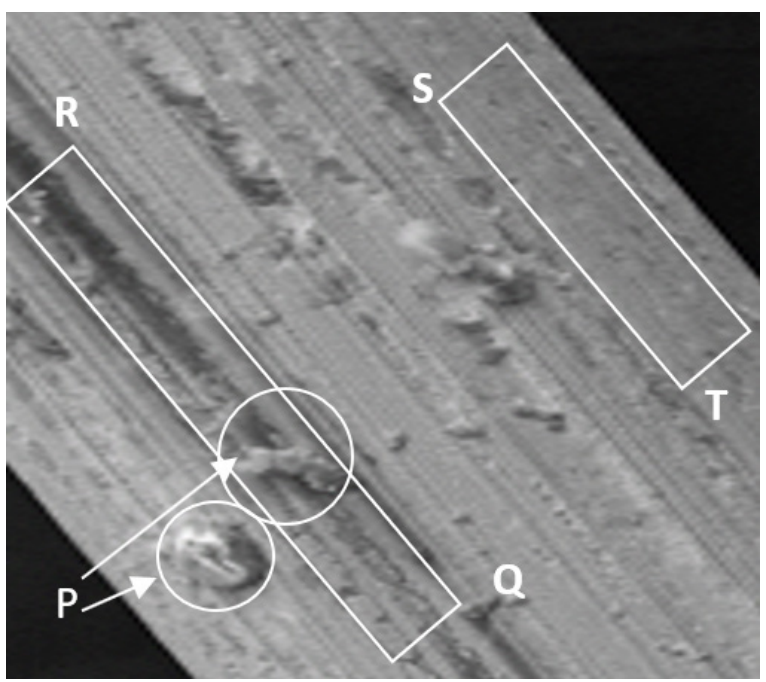

Fig. 8. SEM photograph of wire electrode wear

\section{MULTI-OBJECTIVE OPTIMIZATION A ND VALIDATION OF PREDICTION}

In this stage, the combination of experimental parameters and their response based on the standard ranges defined for the responses are predicted [22]. Based on the desirability function, techniques were used to predict the best results of both responses. This process detects a point that improves the desirability function [23]. For validating the developed models, some solutions were selected randomly. The optimized predicted values of the output responses were compared to experimentally obtained values [24]. The combination of variables that presents the overall optimum desirability (99\%) of response and contour plots is displayed in Fig. 8. Considering all the quality attributes and using the optimization method with 
Table 7. Predicted Results from desirability and validation by confirmation experiments

\begin{tabular}{ccccccccc}
\hline No & $C[\mathrm{~A}]$ & $P W[\mu \mathrm{s}]$ & $P I[\mu \mathrm{s}]$ & $F[\mathrm{ml} / \mathrm{min}]$ & $M R R[\mathrm{~mm} 3 / \mathrm{min}]$ & $W W R$ & Description \\
\hline 1 & 5 & 25 & 75 & 20 & 10.91 & 0.59 & Desirability Approach \\
\hline 2 & 5 & 25 & 75 & 20 & 11.00 & 0.62 & Near-dry WEDM \\
\hline 3 & 5 & 25 & 75 & 2 litres/min & 17.42 & 0.83 & Conventional WEDM \\
\hline
\end{tabular}

which the quality parameters were put into standard ranges (MRR and $W W R$ ), formulation one consisting of $25 \mu$ s pulse-width, $75 \mu$ s pulse-interval, 5 A current, and $20 \mathrm{ml} / \mathrm{min}$ flow rate was selected as having the maximum desirability. The combined optimizing responses are predicted as $10.91 \mathrm{~mm}^{3} / \mathrm{min}$ of material removal rate, and 0.59 of $W W R$.

Confirmation tests were conducted to validate the predicted optimum process parameters for best $M R R$ and $W W R$, as shown in Table 7. The multi-optimization results were confirmed by the mean observed values of the test. The $5 \mathrm{~A}$ current, pulse-width $25 \mu \mathrm{s}$, pulse-interval $75 \mu \mathrm{s}$, and $20 \mathrm{ml} / \mathrm{min}$ flow rate gives $11 \mathrm{~mm}^{3} / \mathrm{min}$ of $M R R$ and $0.62 \%$ of $W W R$.

The desirability principles were applied to obtain the multi-objective solutions to optimize both responses. It is very useful for machine operators to select the best process parameters for minimum $W W R$ and maximum MRR. These results are used by WEDM machine manufacturers to fix the best (default) setting for cryogenically cooled oxygen-mist near-dry wire-cut electrical discharge machining (NDWEDM) process.

\section{COMPARISON OF CRYOGENICALLY COOLED NEAR-DRY AND CONVENTIONAL WEDM}

The predicted best combinations of input parameters were considered for the comparative analysis. In Fig. 9, the $M R R$ and $W W R$ of cryogenically cooled near-dry WEDM are compared with the conventional process. The range of input parameters of both processes are current $5 \mathrm{~A}$, pulse-width $25 \mu \mathrm{s}$, and pulse-interval 75 $\mu \mathrm{s}$. The flow rate of oxygen-mist of near-dry WEDM is $20 \mathrm{ml} / \mathrm{min}$, and the water flow rate of conventional WEDM is $21 / \mathrm{min}$. As per the literature, the near-dry WEDM is an effective eco-friendly process while comparing with conventional WEDM [4], [13] to [15]. The $M R R$ of the near-dry WEDM process was comparatively lower than the conventional process due to the significant flush out of removed material from the workpiece. The $W W R$ of the near-dry process is lower than conventional WEDM because the heat dissipation from the wire is improved by increasing the thermal conductivity of the cryogenic cooling wire [16]. The minimum $W W R$ promotes the life of reusable wire electrode.

\section{CONCLUSIONS}

In this research, data were collected from the experiments of oxygen-mist cryo-cooled wire neardry WEDM were carried out to maintain enough temperature in the cutting zone to cut the Inconel 718 alloy material. The electrical conductivity of cryogenically cooled molybdenum wire was significantly increased in the near-dry WEDM process. It was observed that pulse-width, pulseinterval, current, and flow rate are significant parameters on the material removal rate and wire wear ratio. The current and pulse-width are the most important factors for material removal rate. Increasing the current and pulse-width, the material removal rate
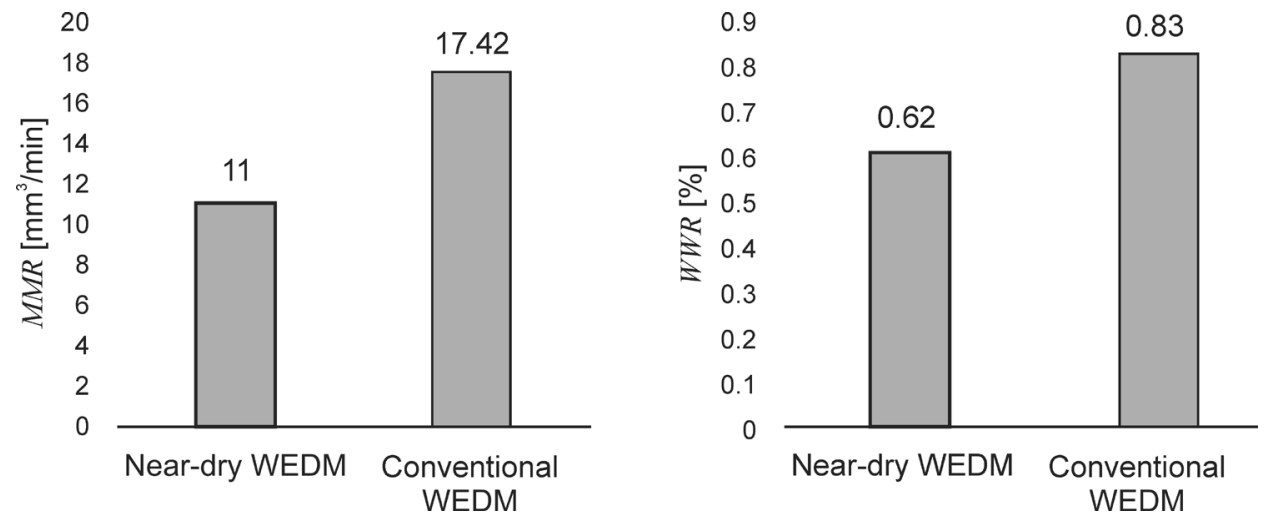

Fig. 9. Comparisons of machining performances between cryogenically cooled near-dry and conventional WEDM 
was increasing and same time decreasing the WWR. While increasing pulse-interval from $45 \mu$ s to 75 $\mu \mathrm{s}$, both the material removal rate and WWR were decreased. The WWR has been significantly reduced at the dielectric fluid flow rate of $20 \mathrm{ml} / \mathrm{min}$. It was observed from the SEM photograph that the wire wear rate is linear to the axis, and the wear rate is high along the spark path of the wire tool. Thus, the optimum process parameters were obtained for the cryo-cooled molybdenum wire electrode used in the oxygen-mist near-dry wire-cut electrical discharge machining process. The desirability technique was used to find the best solution among the conflict behaviour of $M R R$ and $W W R$. It was observed that the behaviour of the parameters against response variables is the same as with the response surface method. The current $5 \mathrm{~A}$, pulse-width $25 \mu \mathrm{s}$, pulse-interval $75 \mu \mathrm{s}$, and $1 \mathrm{ml} / \mathrm{min}$ flow rate give $10.97 \mathrm{~mm}^{3} / \mathrm{min}$ of $M R R$ and 0.59 of $W W R$. The multi-optimization results were validated by the mean observation value of confirmation experiments. These results are used by manufacturers and operators to fix the best (default) setting for the cryogenically cooled oxygen-mist NDWEDM process.

In near-dry WEDM, the cryogenically cooling of wire significantly contributed to reducing $W W R$ than to $M R R$. While comparing conventional WEDM, the $W W R$ of near-dry WEDM was very lower. The lowest $W W R$ increases the life of reusable molybdenum wire tools. As per the literature, the near-dry WEDM is an effective eco-friendly process while comparing with conventional WEDM. However, the MRR of near-dry WEDM is lower than that of the conventional WEDM process.

\section{ACKNOWLEDGEMENTS}

This research was conducted in the Bannariamman Institute of Technology, Erode, Tamilnadu, India. for the data collection, and interpretation of results to submit the article for publication.

\section{NOMENCLATURES}

$\begin{array}{ll}P W & \text { pulse-width, }[\mu \mathrm{s}] \\ P I & \text { pulse-interval, }[\mu \mathrm{s}] \\ C & \text { spark current, [A] } \\ \mathrm{F} & \text { flowrate, [ml } / \mathrm{s}] \\ M R R & \text { material removal rate }\left[\mathrm{mm}^{3} / \mathrm{min}\right] \\ W W R & \text { wire wear ratio [-] } \\ f(x) & \text { Function of ' } x \text { ' } \\ x_{1}, x_{2}, \ldots, x_{n} & \text { independent variables } \\ \beta_{0}, \beta_{i}, \beta_{\mathrm{ij}} & \text { model coefficients }\end{array}$

$\phi$

$R^{2}$

FI

$F$-value

\author{
statistical error \\ coefficient of determination \\ factor interaction \\ Values from statistical " $F$ ” table
}

\section{REFERENCES}

[1] Shabgard, M.R., Seyedzavvar, M., Oliaei, S.N.B. (2011). Influence of input parameters on the characteristics of the EDM process. Strojniski vestnik - Journal of Mechanical Engineering, vol. 57, no. 9, p. 689-696, Dol:10.5545/svjme.2011.035.

[2] Munoz, A.A., Sheng, P. (1995). An analytical approach for determining the environmental impact of machining processes. Journal of Materials Processing Technology, vol. 53, no. 3-4, p. 736-758, Dol:10.1016/0924-0136(94)01764-R.

[3] Yeo, S.H., Tan, H.C., New, A.K. (1998). Assessment of waste streams in electric-discharge machining for environmental impact analysis. Proceedings of the Institution of Mechanical Engineers, Part B: Journal of Engineering Manufacture, vol. 212, no. 5, p. 393-400, Dol:10.1243/0954405981515996.

[4] Hewidy, M.S., El-Taweel, T.A., El-Safty, M.F. (2005). Modelling the machining parameters of wire electrical discharge machining of Inconel 601 using RSM. Journal of Materials Processing Technology, vol. 169, no. 2, p. 328-336, D0l:10.1016/j.jmatprotec.2005.04.078.

[5] Boopathi, S., Sivakumar, K. (2016). Optimal parameter prediction of oxygen-mist near-dry Wire-cut EDM. International Journal of Manufacturing Technology and Management, vol. 30, no. 3-4, p. 164-178, DOI:10.1504/IJMTM.2016.077812.

[6] Abdulkareem, S., Khan, A.A., Konneh, M. (2009). Reducing electrode wear ratio using cryogenic cooling during electrical discharge machining. International Journal of Advanced Manufacturing Technology, vol. 45, no. 11-12, p. 1146-1151, DOI:10.1007/s00170-009-2060-5.

[7] Saha, S.K., Choudhury, S.K. (2009). Experimental investigation and empirical modeling of the dry electric discharge machining process. International Journal of Machine Tools and Manufacture, vol. 49, no. 3-4, p. 297-308, D0l:10.1016/j. ijmachtools.2008.10.012.

[8] Jiang, Z., Zhang, H., Sutherland, J.W. (2012). Development of an environmental performance assessment method for manufacturing process plans. International Journal of Advanced Manufacturing Technology, vol. 58, no. 5-8, p. 783790, DOI:10.1007/s00170-011-3410-7.

[9] Bai, X., Zhang, Q.-H., Yang, T.-Y., Zhang, J.-H. (2013). Research on material removal rate of powder mixed near dry electrical discharge machining. International Journal of Advanced Manufacturing Technology, vol. 68, no. 5-8, p. 1757-1766, D0l:10.1007/s00170-013-4973-2.

[10] Boopathi, S., Sivakumar, K. (2013). Experimental investigation and parameter optimization of near-dry wire-cut electrical discharge machining using multi-objective evolutionary algorithm. International Journal of Advanced Manufacturing Technology, vol. 67, p. 2639-2655, Dol:10.1007/s00170-0124680-4. 
[11] Boopathi, S. (2012). Experimental comparative study of neardry wire-cut electrical discharge machining (WEDM). European Journal of Scientific Research, vol. 75, no. 4, p. 472-481.

[12] Boopathi, S., Sivakumar, K. (2014). Study of water assisted dry wire-cut electrical discharge machining. Indian Journal of Engineering and Materials Sciences, vol. 21, no. 1, p. 75-82.

[13] Rajyalakshmi, G., Venkata Ramaiah, P. (2013). Multiple process parameter optimization of wire electrical discharge machining on Inconel 825 using Taguchi grey relational analysis. International Journal of Advanced Manufacturing Technology, vol. 69, p. 1249-1262, D0l:10.1007/s00170-0135081-z.

[14] Garg, M.P., Kumar, A., Sahu, C.K. (2017). Mathematical modeling and analysis of WEDM machining parameters of nickel-based super alloy using response surface methodology. Sadhana - Academy Proceedings in Engineering Sciences, vol. 42, no. 6, p. 981-1005, D0l:10.1007/s12046-017-0647-3.

[15] Nayak, B.B., Mahapatra, S.S. (2016). Optimization of WEDM process parameters using deep cryo-treated Inconel 718 as work material. Engineering Science and Technology, an International Journal, vol. 19, no. 1, p. 161-170, D0I:10.1016/j.jestch.2015.06.009.

[16] Myilsamy, S., Boopathi, S., Yuvaraj, D. (2021). A study on cryogenically treated molybdenum wire electrode. Materials Today: Proceedings, vol. 45, p. 8130-8135, D0l:10.1016/j. matpr.2021.02.049.

[17] Shather, S.K., Mohammed, M.T. (2018). Investigate WEDM process parameters on wire wear ratio, material removal rate and surface roughness of steel 1012 AISI. Engineering and Technology Journal, vol. 36, no. 3, p. 256-261, D0l:10.30684/ etj.36.3A.3.

[18] Boopathi, S. (2019). Experimental investigation and parameter analysis of LPG refrigeration system using Taguchi method. SN
Applied Sciences, vol. 1, no. 8, p. 892, D0l:10.1007/s42452. 019-0925-2.

[19] Boopathi, S., Sivakumar, K., Kalidas, R. (2012). Parametric study of dry WEDM using Taguchi method. International Journal of Engineering Research and Development, vol. 2, no. 4, p. 63-68.

[20] Pandey, H., Dhakar, K., Dvivedi, A., Kumar, P. (2015). Parametric investigation and optimization of near-dry electrical discharge machining. Journal of Scientific and Industrial Research, vol. 74, no. 9, p. 508-511.

[21] Singh, J., Sharma, R.K. (2017). Green EDM strategies to minimize environmental impact and improve process efficiency. Journal for Manufacturing Science and Production, vol. 16, p 1-18, D0l:10.1515/jmsp-2016-0034.

[22] Srivastava, M., Maheshwari, S., Kundra, T., Rathee, S. (2017). Multi-response optimization of fused deposition modelling process parameters of ABS using response surface methodology (RSM)-based desirability analysis. Materials Today: Proceedings, vol. 4, no. 2, p. 1972-1977, D0I:10.1016/j.matpr.2017.02.043.

[23] Senthil, S.M., Parameshwaran, R., Ragu Nathan, S., Bhuvanesh Kumar, M., Deepandurai, K. (2020). A multi-objective optimization of the friction stir welding process using RSMbased-desirability function approach for joining aluminum alloy 6063-T6 pipes. Structural and Multidisciplinary Optimization, vol. 62, p. 1117-1133, D0l:10.1007/s00158-020-02542-2.

[24] Vahdati, M., Moradi, M., Shamsborhan, M. (2020). Modeling and optimization of the yield strength and tensile strength of Al7075 butt joint produced by FSW and SFSW using RSM and desirability function method. Transactions of the Indian Institute of Metals, vol. 73, p. 2587-2600, D0l:10.1007/ s12666-020-02075-8. 